\title{
ACCESSIBILITY AND QUALITY OF MENTAL HEALTH CARE FOR FOREIGNERS IN PRAGUE ${ }^{1}$
}

\author{
Martin Tušl \& Markéta Niederlová
}

\begin{abstract}
The present study aims to explore the accessibility and the quality of mental health care for foreigners in Prague. Introduction briefly outlines the situation of immigration and foreign population in the Czech Republic, with a particular focus on the capital city. Further, risk factors that are associated with mental health of foreigners who live in the Czech Republic are discussed. A summary about culturally competent practice in mental health care and the current state of the Czech mental health care conclude this section.

Empirical part explores foreigners' experience with mental health services in Prague and identifies the principal barriers that hinder their access to a good quality care. The sample was composed of 27 participants, of which 20 were English and 7 Russian speaking. Data collection was conducted primarily via an online questionnaire and several semi-structured interviews. The findings identified four principal barriers that adversely impact the accessibility: cost, language, information, accessibility, and two barriers that adversely impact the quality (professionalism, cultural differences) of mental health care for foreigners. In the last part outcomes of the research are discussed and possible ways that could lead to an improvement of the current situation are suggested. Finally, we provide a brief overview of mental health institutions in Prague where foreigners may seek help.
\end{abstract}

Keywords: mental health, foreigners in Prague, intercultural psychology, cultural competency, qualitative research

Received: 22. 10. 2017

Approved: 13.11. 2018

Published online: 29. 12. 2018

Updated: 25. 2. 2019

\footnotetext{
${ }^{1}$ The study was supported by the Charles University program Progress Q15 "Life course, lifestyle and quality of life from the perspective of individual adaptation and the relationship of the actors and institutions."
} 


\section{INTRODUCTION}

The number of foreigners living in the Czech Republic has constantly been increasing every year since the fall of the communist regime in 1989. Back in 1993, there were 31 thousand foreigners registered with permanent residence and the number has reached 272 thousand in 2016. Today there is almost half a million foreigners living in the Czech Republic, including the foreigners with long-term residence over 90 days. They represent about $4,5 \%$ of the total population (Český statistický úrad, 2016). Prague, the capital city, concentrates more foreigners than any other region of the country. It is one of the most popular European tourist destinations and Prague is sometimes better known among foreigners than the country itself. There were approximately 160 thousand registered foreigners ${ }^{2}$ in 2016 , representing about $12,7 \%$ of the total population of Prague (Český statistický úřad, 2016).

Diversification of the population is not just the case of the Czech Republic, it is a phenomenon of the modern world, and cultural pluralism has become common in many Western societies (Berry, 1997). Nonetheless, it is relatively new phenomenon for the Czech Republic and the other countries of the former Eastern Bloc. During the era of the Cold War, the countries of the Eastern Europe were cut off from the West by an imaginary Iron Curtain, which was impossible to cross it until the late 80's. When the Soviet Union started to fall apart in the 90's, the borders of the Czech Republic and other communist countries opened to the new populations and cultures after almost 50 years of isolation.

Globalization and migration create challenges in many areas and health care is not an exception. Health care system must be capable of providing a good quality service not only to local, in this case Czech population, but to all inhabitants. In this regard, mental health care is a more challenging area compared to the general medical care because mental health practitioners' work relies profoundly on language (Bauer \& Alegría, 2010). For the main part, during the initial psychological assessment most of the key information is accessible only via verbal communication and, similarly, verbal communication is the principal way of treatment in psychotherapy (Aklin \& Turner, 2006; Martinez, 2013). As such, one of the vital requirements for practitioners who want to successfully work with foreign clients is a foreign language proficiency.

\section{Challenges associated with immigrants' life in the Czech Republic}

Settling in a new country can be very challenging. People have to cope with various unknown situations. To list some: they may struggle with the language barrier, they may lack satisfying social environment, experience financial problems, experience prejudice and discrimination, and in general, they are exposed to many stressful situations that are associated with the process of acculturation (American Psychological Association [APA], 2013; Kirmayer et al., 2011). As a result, immigrants are at a greater risk of developing stress-related mental health problems such as depression or anxiety (APA, 2013; Betancourt et al. 2003; Hubinková et al., 2011).

Language barrier is one of the common challenges that foreigners must face in the Czech Republic. Basic everyday communication can become a source of anxiety and frustration. Especially immigrants from the Western countries often struggle with the language. Czech is a Slavic language and it differs considerably from the Germanic and the Romance languages, such as English or French. As such, it is extremely challenging to learn Czech and foreigners often experience difficulties with the language even after having spent a considerable time in the country. Dealing with institutions, offices, and officers, everyday situations such as shopping, transportation assistance, police, etc., can become very stressful for foreigners who

\footnotetext{
${ }^{2}$ Excluding the Slovak nationals
} 
are not able to communicate in Czech. Therefore, the language barrier needs to be considered as a significant stressor in the Czech context as it can substantially complicate one's everyday life and well-being (APA, 2013).

People from different cultural groups are at risk of being subjected to biased views and stereotypes (Allport, 1958; APA, 2013). Creating stereotypes about other groups of people around us is a natural process that helps us orient efficiently in unknown situations. Stereotypes can be either positive, neutral or negative (Neuliep, 2014). Negative stereotypes can lead to prejudice and may further escalate into discrimination and racism (Allport, 1958; Neuliep, 2014). Physical features of individuals (e.g. race, ethnicity) that are uncommon in the country are often subject to strong stereotypes (APA, 2013; Berry, 1997). The population of the Czech Republic is racially mostly homogenous, and the majority of the population is Caucasian. Therefore, people of other races are likely to experience the adverse impact of racial stereotypes. Discrimination and racism can have serious consequences when it comes to mental health as they are associated with higher risk of psychological distress and the development of mental health problems (APA, 2013; Betancourt et al., 2003; U.S. Department of Health and Human Services [USDHHS], 2001).

Migration often implies that immigrants lose their social ties in their home country and they may also struggle with establishing new relationship within the local population, particularly if they cannot communicate in the local language. Moreover, early negative experience with the local population may favor an attitude of hostility towards the people from the new environment. As a consequence, foreigners may feel physically and psychologically isolated both from the society in their home and in the new country. Loneliness and feelings of alienation are both important risk factors to the development of mental health problems (APA, 2013; Hubinková et al., 2011; Kirmayer et al., 2011).

\section{Cultural competence in mental health care}

Mental illness stems from a combination of biological, psychological, social, and cultural factors (USDHHS, 2001). Culture shapes one's values, beliefs, and behaviors about mental health, mental illness, and possible ways of treatment (Aklin \& Turner, 2006; Bennegadi, 2009; Kirmayer, 2012). Specifically, it influences how individuals perceive the cause of an illness, how they recognize and express the symptoms, what coping strategies they use to deal with distress, what sort of treatment they seek, and what expectations they have about the treatment and its outcomes (Betancourt et al., 2003; Betancourt, 2004; Jacob, 2014; Kirmayer, 2012; Marsella \& Yamada, 2013). Also, cultural differences between a practitioner and a client may lead to different views about what is normal and pathological behavior (Jacob, 2014; Marsella \& Yamada, 2013). Culturally competent mental health care seeks to make the services accessible and efficient for people with different ethnocultural backgrounds (Kirmayer, 2012). Cultural competence can be evaluated at two levels - individual and structural. The former regards the cultural competence of a given practitioner and his or her personal ability to work with culturally different clients. The latter defines how the system seeks to make mental health services accessible equally for all people regardless their cultural group (APA, 2003, 2013; Betancourt et al., 2003; Kirmayer, 2012).

Individual cultural competence consists of three areas that one can develop - knowledge, attitude, and skills (APA, 2003, 2013; Bennegadi, 2009). First, culturally competent mental health practitioners should be knowledgeable about their clients' culture. This can be achieved mainly through a personal contact with the culture. The more one seeks contact with other cultural groups, the more knowledgeable and competent one becomes in intercultural communication, and the less one is at risk of having biased views of the culture (Allport, 1958). 
A lack of knowledge about cultural differences can prevent the practitioner from obtaining relevant information which can consequently lead to misinterpreting and a wrong evaluation of the problem (Kirmayer et al., 2011). In contrast, being knowledgeable about the client's culture and attentive to its specifics can facilitate the rapport between the practitioner and the client, and allow collection of information important for the diagnostic evaluation. Moreover, it can enhance client's trust in the practitioner his or her engagement and adherence to the treatment process (Jacob, 2014).

Further, culturally competent practitioners should be aware of their attitudes and beliefs toward culturally different clients and understand how these may influence their interaction with the clients. They should pay a particular attention to the origin of their attitudes toward them. Biased attitudes based on stereotyped views of a certain cultural group can be daunting in the clinical practice (APA, 2013). Stereotyped views lead to wrong opinions about a person's feelings and behavior and they may prevent the practitioner from recognizing the client's individuality. As a result, the practitioner is more likely to make poor clinical judgments, that do not reflect the individuality of the client but rather the biased expectations of the practitioner (Alcántra \& Gone, 2014). Moreover, stereotyped views can create problems in the establishment of the rapport between a practitioner and the client (Draguns \& Tanaka-Matsumi, 2003).

Finally, mental health practitioners should use culturally sensitive tools and interventions that are tailored to the culture of a particular client. Intercultural setting may require the use of culturally adapted interventions. Sometimes it may be necessary to modify the style of interaction with a client, use a foreign language, or become familiar with some types of interventions that come from the cultural traditions of the client (APA, 2013; Kirmayer, 2012). Individual cultural competence is based on the principles of client-centered care that includes exploration, empathy, and attentiveness to clients' values, preferences, and demands. Culturally competent practitioners should have knowledge and attitudes that facilitate cross-cultural interactions, and they should use interventions that are sensitive and appropriate to their clients' culture (APA, 2003, 2013; Arasaratnam \& Doerfel, 2005; Betancourt, 2004; Betancourt et al., 2003).

Addressing cultural competence is equally important on the structural level within a society. Models of mental health care and mental health institutions are socially construed and vary culturally. Variations in the structural level of cultural competence occur particularly in how societies address and view services for culturally different groups that live in the society, and how they make the services accessible to these populations (Kirmayer, 2012). Cultural characteristics of the dominant society shape the way how, why, when, and where its members seek mental health care. Also, the institutions and the authorities of the dominant society decide which mental health problems are recognized and in what ways they are addressed (APA, 2013).

In order to attend to all relevant cultural groups, mental health institutions should dispose of practitioners that are representative of the population in the society. They should ensure that clients of different cultural backgrounds can access the services they need. On a basic level, this can be achieved through linguistic support, interpreter service, translations of documents and information about the services in different languages (Betancourt et al. 2003). Further, the system of mental health care should promote a culturally appropriate care through the development of specific tools and measures, and promotion of culturally competent practice among practitioners (Aklin \& Turner, 2006; Kirmayer, 2012). 


\section{In the context of the Czech mental health care system}

Mental health care in the Czech Republic struggles with many problems that most Western countries have already overcome, and the situation is still far from being favorable. To list some of the most critical issues, Czech mental health care suffers from extreme underinvestment, persistent institutionalized care situated in large hospitals, lack of social care and communitybased services (short-term stay clinics), lack of adequate crisis intervention, persisting stigma towards mental health care in the society, and the absence of national mental health legislation (Höschl, Winkler, \& Pěč, 2012; Raboch \& Wenigová, 2012; Winkler, Csémy, Janoušková, \& Krejníková, 2013).

In fact, the accessibility and the quality of mental health care is often inappropriate even for the Czech population. Nonetheless, the system has been undergoing a thorough reform initiated in 2013, which aims to tackle most of the aforementioned issues (Ministerstvo zdravotnictví ČR, 2013). In this context, we believe it is important to raise the issue of intercultural mental health care and focus the reform not only on the Czech population, but also consider the large foreign population that equally needs access to an appropriate mental health care.

\section{Present study}

The present paper focuses on intercultural mental health care in the capital of the Czech Republic. Specifically, it aims at the Anglophone and Russian-speaking communities which represent the largest immigrant communities, and they often have none or only limited proficiency in the Czech language. As such, they are prone to experience difficulties when accessing mental health care. Nowadays, English is used as a lingua franca among many nonnative speakers and it is the principal communicational language of foreigners from the EU and other Western countries in Prague. In the same way, Russian is often used as the principal language of communication among immigrants from the Eastern countries such as Russia, Ukraine or Belarus. To our knowledge, this study represents a pioneer work that provides an insight into the intercultural mental health care in Prague.

\section{METHODS}

We used a qualitative design to explore foreigners' experience with mental health services in Prague from emic perspective. The initial research question of the study was: "What is the level of accessibility and quality of mental health care for foreigners (non-Czech/Slovak population) in Prague?" Two principal methods were used for the data collection - an online questionnaire and a semi-structured interview. Given the sensitivity of the explored topic, we decided to use an anonymous online survey to gather the specific data. Part was later to developed through individual face-to-face interviews. Our aim was to explore foreigners' experience with mental health care services in Prague; how they access and use mental health care services in Prague; and what are the principal barriers that they experience in accessing and using mental health care services in Prague.

\section{Procedure}

Initially, the data were gathered through an online questionnaire (Questionnaire $\mathrm{A}^{3}$ ) that was designed specifically for the purpose of our study. It was administered through a web-based survey provider. Pilot version of the questionnaire was prepared in English and a sample of 3 participants tested it. The final version consisted of 28 items in form of multiple choice and open questions, and the English version was then translated into Russian. Questionnaire A was

\footnotetext{
${ }^{3}$ See Appendix
} 
posted in Facebook groups that are frequented by foreigners who live in Prague (e.g. Foreigners living in Prague). The advertisement informed about the research, specified the population that was searched for and briefly explained the purpose and the goals of the study. An email account ${ }^{4}$ was created where participants could write any inquiries about the research. Participation in the research was voluntary and the participants did not receive any financial or other reward.

Participants that filled out the questionnaire were granted anonymity. However, if they wished to participate in a face-to-face interview, they were asked to leave their email address at the end of the questionnaire. In the next step, participants that provided their email address were contacted with a request for an interview and individual semi-structured interviews were conducted. Questions for the interview were based on the answers that participants provided in the Questionnaire A, in order to get a better understanding of the participants' experience. Participants were asked for a permission to record the interview to which all, but one interviewee, consented. Further information was gathered through phone calls and email correspondence with practitioners, to evaluate the availability and accessibility of the information that foreigners can find when seeking mental health services in Prague. Other information sources consisted of hospitals' and clinics' websites, practitioners' websites, information websites for expatriates in Prague, information book-lets for Prague expatriates, field visits to Prague hospitals and clinics and interviews with practitioners.

\section{Sample}

Data collection was conducted during a period of two months from March 2017 to April 2017. Inclusion criteria for participation were: (a) adult age, (b) other nationality than Czech or Slovak, (c) experience with mental health services in Prague. Questionnaire A was completed by 27 participants -20 filled out the English version, and 7 participants the Russian version of the questionnaire. The sample was composed mostly of female participants (24), the most frequent age category was 26-35, and the most frequent nationality was American (8) and Russian (6). All but one participants were actively working. All of the participants had been living in Prague for more than 1 year, and 12 participants for more than 10 years (see Table 1). A contact email address was provided by 12 participants, and 7 responded to the request for an interview. Face-to-face interviews were conducted with 5 participants, 1 participant wished to be interviewed over the phone, and 1 via email communication. The interview sample was composed of 6 females (3 Americans, 1 Albanian, 1 Norwegian, 1 Ukrainian) and 1 male (Portuguese).

\footnotetext{
${ }^{4}$ mental.health.prague@gmail.com
}

Table 1

Sociodemographic characteristics of the sample

\begin{tabular}{lccc}
\hline Age & & Female $(N=24)$ & Male $(N=3)$ \\
\hline $18-25$ & 2 & - \\
$26-35$ & 12 & 2 \\
$36-45$ & 4 & 1 \\
& $46-55$ & 6 & - \\
\hline
\end{tabular}

\begin{tabular}{|c|c|c|}
\hline \multicolumn{3}{|l|}{ Nationality } \\
\hline USA & 7 & 1 \\
\hline Russia & 6 & - \\
\hline UK & 3 & - \\
\hline Ukraine & 3 & - \\
\hline Austria & 1 & - \\
\hline Albania & 1 & - \\
\hline Germany & - & 1 \\
\hline Norway & 1 & - \\
\hline Portugal & - & 1 \\
\hline Romania & 1 & - \\
\hline Turkey & 1 & - \\
\hline \multicolumn{3}{|l|}{ Years in Prague } \\
\hline $1-3$ years & 5 & 1 \\
\hline 4-7 years & 8 & 1 \\
\hline $8-10$ years & - & - \\
\hline$>10$ years & 9 & 1 \\
\hline$>20$ years & 2 & - \\
\hline
\end{tabular}




\section{Data Analysis}

Qualitative data from Questionnaire A and from the interviews were transcribed and carefully read several times by the researcher to get a general idea of the main themes. Content analysis of the qualitative data aimed to identify the sub-categories (barriers) associated with two principal categories - accessibility and quality. The main items of Questionnaire A for the analysis included: 'What were the main barriers that you have encountered in accessing mental health services?' 'Did you feel comfortable communicating with the psychologist? What made you feel comfortable/uncomfortable?' 'Did you feel that the psychologist understood well all aspects of your problem? What made you feel this way?' 'What were the main positives and negatives of your experience?' 'Would you have any suggestions on how to improve the accessibility and quality of mental health services for foreigners in Prague?'

Qualitative data were organized into units that were analyzed and coded according to the themes they reflected. They were subsequently grouped according to the barrier they represented (see Table 2). In total, 44 units were analyzed and 6 principal barriers were identified. Apart from the barriers, participants were also asked about their positive experience and their answers were grouped into one separate category.

Table 2

Examples from the analysis

\begin{tabular}{|c|c|c|c|}
\hline Unit & Theme & Barrier & Category \\
\hline $\begin{array}{l}\text { "After a year of struggling, I finally found a } \\
\text { therapist I can stick with, but I pay more than I can } \\
\text { afford because the English sessions aren't covered } \\
\text { by insurance." }\end{array}$ & $\begin{array}{l}\text { Expensive therapy, } \\
\text { insurance }\end{array}$ & Cost & Accessibility \\
\hline "It was very difficult to find one who spoke English" & $\begin{array}{l}\text { Lack of English } \\
\text { speaking therapists }\end{array}$ & Language & Accessibility \\
\hline $\begin{array}{l}\text { "I would like more information, recommendations. } \\
\text { Each psychologist has his own site, where he } \\
\text { publishes only positive reviews, but there is no } \\
\text { objective information." }\end{array}$ & $\begin{array}{l}\text { Lack of reliable } \\
\text { information }\end{array}$ & Information & Accessibility \\
\hline $\begin{array}{l}\text { "It took over a month to get an appointment } \\
\text { despite the situation being very urgent." }\end{array}$ & Long waiting times & Availability & Accessibility \\
\hline $\begin{array}{l}\text { "The two that I found and visited were incompetent, } \\
\text { did not take me seriously." }\end{array}$ & $\begin{array}{l}\text { Lack of } \\
\text { competency }\end{array}$ & Professionalism & Quality \\
\hline $\begin{array}{l}\text { "The gender politics in the Czech Republic feels } \\
\text { very traditional to me, and I feel like I need to work } \\
\text { doubly hard to be taken seriously because I'm a } \\
\text { woman." }\end{array}$ & $\begin{array}{l}\text { Difference in } \\
\text { gender politics }\end{array}$ & $\begin{array}{c}\text { Cultural } \\
\text { difference }\end{array}$ & Quality \\
\hline $\begin{array}{l}\text { "Finally I got to see someone whose English was } \\
\text { great, who actually listened to me when I talked and } \\
\text { seemed to actually want to help me and be happy } \\
\text { about offering me the services. That was awesome! }\end{array}$ & $\begin{array}{l}\text { English } \\
\text { proficiency, } \\
\text { attentiveness, } \\
\text { positive attitude }\end{array}$ & - & $\begin{array}{c}\text { Positive } \\
\text { experience }\end{array}$ \\
\hline
\end{tabular}




\section{RESULTS}

Participants were asked about the reason for seeking mental health care ${ }^{5}$. The most frequent problems were anxiety and depression $(N=7)$, and issues related to family and relationships $(N=5)$. The majority of participants sought mental health care via internet $(N=16)$ and friend referral $(N=15)$, other ways included GP referral $(N=6)$, street flyer $(N=1)$, and social services $(N=1)$. Most of the participants $(N=23)$ saw a private mental health practitioner, and 7 participants had an experience with a public institution.

Analysis of the qualitative data yielded six principal categories/barriers associated with the accessibility and the quality of mental health care for foreigners (see Table 2). Principal barriers in regard to accessibility were: language, high cost of services, lack of information, and low availability of practitioners. Principal barriers related to the quality were: lack of professionalism and cultural differences. All the categories are discussed below and more examples are given for each category. Answers related to participants' positive experience are provided in a separate category.

\section{A) Accessibility}

\section{Cost}

High cost of the services was the most common barrier that participants mentioned. It was particularly prevalent when accessing private mental health practitioners.

"My therapist charges 500 crowns per session and I think that is affordable for most of my working experiences and I also think it would be worth it because I value mental health. But sometimes a good therapist is no longer 500, sometimes they charge more and that just wouldn't be affordable for me. Like prices around 1000 crowns that's unaffordable for me, even though at the moment I'm at a high position at work and my salary is very good I couldn't afford a 1000 session, maybe only if I desperately need it. But if I was to spend 4000 crowns of my salary per month for psychotherapy it would be too much." (Albanian female)

“...if I was paying 200 crowns to visit a doctor I can afford that, but when its 500 crowns or 1000 crowns, only rich people can go basically, but then regular patients can't afford it and they are usually the ones who need it the most but they don't have the money. So I think the best solution would be that the insurance covers more. Probably around 3-400 crowns would be a good balance for psychotherapy. But obviously prices around 1000 crowns per session are out of the question. And I mean I'm not poor I earn an average salary in Prague but I certainly don't have that much money that I could pay 1000 crowns a week for therapy." (American female)

Further, insurance was an important topic that many participants raised with regards to the cost of mental health care. Foreigners who do not have access to public health insurance do not get any refund for psychotherapy, nor for medication even if treated in a public institution.

"After a year of struggling, I finally found a therapist I can stick with, but I pay more than I can afford because the English sessions aren't covered by insurance. And it would never have taken me a year to get real help if I spoke Czech. There are frighteningly few avenues to help English speakers find help for mental issues." (Norwegian female)

"Private insurance for foreigners does not cover any psychiatric care and I had to pay for everything out of pocket. It was very expensive even for one visit and I would have to pay for all medications myself." (American female)

\footnotetext{
5 'Could you briefly describe the reason for your visit?' (item 10)
} 
Also, one participant mentioned an experience with double fees when accessing private mental health services. Private practitioners can set the pricing for their services as they wish and in practice, some therapists charge extra fees for foreign language.

"Once I was shocked, there was this child psychologist and he has a website in Czech and a website in English and he charges more for English than for Czech because he considers it to be an extra service. So in Czech it was 800 crowns per hour but for an hour in English 1200 crowns. " (American female)

\section{Language}

Language was the second most common barrier. It is mostly prevalent, that in public institutions can be extremely difficult for foreigners to reach an appropriate care if they do not speak Czech. To illustrate, the following excerpt is retrieved from an interview with a young Norwegian woman, who was advised to contact Bohnice mental clinic.

"I was feeling very hopeful because I'd heard that Bohnice is the place where they can help and I was like 'if anywhere they can help me, this must be it'. But I called the number that she gave me and no one spoke English, I was calling from work just when I was feeling really desperate and I needed something like preferably that day. But no one understood me, they handed the phone to someone who said call this number there will be English speakers there, I called that number and they didn't understand me either, eventually they got someone who spoke kind of almost English to tell me to call back after some time, that there would be someone who could speak English better. I was crying on the phone obviously not very happy but I called back after the time they said. There was a nurse who said that I could come that evening and there would be a guy who spoke English, she said to come after 7pm. I came at $7 \mathrm{pm}$ my girlfriend traveled with me, we waited and then like three hours later I got to see the guy and the conversation lasted for about thirty minutes. I could tell he probably had had a very long day by the time he got to me, he basically listened to what I had to say but he seemed to just fall back on whatever was the easiest, he seemed to do just like a quick pseudo-diagnosis and said ok, it seems like you have this issue so I can recommend...well, nothing actually. He gave me information for a private clinic where they have psychologists and psychiatrists and told me to contact them, something in Karlin. And he wrote me this paper, because whenever you go to a public crisis center you have to write this summary of what they learned about you. Obviously it was in Czech and obviously they don't tell you what is on this thing so you have to go home and google translate it..." (Norwegian female)

Further comments regarded the difficulties in reaching qualified English speaking practitioners, if one does not have a personal referral or enough money to afford private therapists.

"I didn't have a problem because I had a personal referral, but some people I know who have sought out care have had difficulty sourcing a psychologist who speaks English fluently enough to communicate with." (American female)

"Without a referral it might have been hard to find someone who spoke English without having to pay a lot of money." (American female)

\section{Information}

Information barrier is intertwined with the language barrier as information about mental health care services are often available only in Czech and thus inaccessible to foreigners who do not speak the language. Also, seeking out reliable information about qualified practitioners who offer help to foreigners can be tricky.

"I know my experience is really bad and I'm sure there are some whose experience was way different from mine, that not all doctors are terrible, probably there are many wonderful ones but I have no idea how to find them. So some database or center for foreigners would be really helpful. I know that I'm not 
in the position to expect that everybody speaks English because it's not an English speaking country, but on the other hand even though I can speak fairly Czech on a conversational level for something like this it's really important to be able to speak your native language." (American female)

"I wanted to find a Russian-speaking psychologist, but there are not enough of them. Since the choice is small, not a single suitable one was eventually found. I would like more information, recommendations. Each psychologist has his own site, where he publishes only positive reviews, but there is no objective information." (Russian female)

\section{Availability}

Long waiting times and difficulties in finding available qualified practitioners who offer help to foreigners was mentioned by several participants as another significant barrier to access mental health care.

"I got an appointment, it was like in three or four weeks, even though I said it was quite urgent but they just said sorry that's all we have." (American female)

"The few psychotherapists recommended to me were either full, prohibitively expensive, often both. Although my Czech is fluent -- I've been here most of my life -- I wanted to see an English-speaking therapist to allow me freer and more direct communication." (American female)

"Price was also a concern and in order for treatment to be covered by VZP", the waiting list was three months." (British female)

\section{B) Quality}

\section{Professionalism}

Several participants complained about the quality of the treatment they had received and felt that they were not treated well. A lack of professionalism was the principal barrier in regard of the quality of mental health services.

"Interested only in my insurance and the money, not in me. I didn't get any appropriate care at all in the sleep clinic. The psychiatrist just gave me a prescription for sleeping pills and that was it." (Ukrainian female)

"When I described an inability to sleep even when taking tranquilizers, paranoia, delusions, and extreme restlessness, all of which lasted for over a month, he brushed it off as "anxiety". I tried to explain other issues as well - including that I'm autistic, hypersensitive, have a severe sleep disorder, and have a history of being abused both in my family and in other relationships - and he didn't seem at all interested in any of that." (American female)

"Despite the fact that the psychologist had a good rating, it seemed to me he did not hear my problem and kept trying to offer me a registration in some kind of HR organization. "(Ukrainian female)

"I said that I had a hard time sleeping so he gave me this document and one sleeping pill to take that night and the number for this therapist place which I had to contact on my own. The guy I saw was a psychiatrist and I was really disappointed because I was really messed up back then and I know that this crisis clinic they have more things that they can offer to someone who comes and is really really desperate than just a pill and a note. But there wasn't even a hint offering me any more help. The whole experience felt to me like I was bothering them, which you don't really want to feel like when you need help." (Norwegian female)

\footnotetext{
${ }^{6}$ Všeobecná zdravotní pojišt'ovna (a public health insurance company)
} 


\section{Cultural differences}

In several cases the quality of the treatment was complicated by cultural differences. Particularly common were different gender role views, that were seen rather traditional in the Czech culture by some female participants in our sample.

"As an American abroad, this is the one thing that I feel most dissatisfied with: the gender politics in the Czech Republic feel very traditional to me, and I feel like I need to work doubly hard to be taken seriously because I'm a woman." (American female)

"I have seen a few different therapists here but one thing that has remained the same would be a shock at some of the things I said I had experienced. I know that in my home city those experiences are very well-known so I was not expecting that. Furthermore, even if it had been completely outlandish it is vital that therapists never show that they are shocked, dismayed, or doubtful." (British female)

"He was an older Czech man and seemed to view me as a young, hysterical woman. He ignored my explanations and I felt it was related to my gender and age. I have never had this experience with an American psychologist or psychotherapist. When I asked the (Czech) friend who had recommended him about this, she said it was normal and not to worry about it." (American female)

\section{C) Positive experience}

Participants were also asked about their positive experience. The first example is retrieved from an interview with a young American woman who shared her positive experience with a crisis intervention center when she suffered a panic attack.

"I remember I was walking through JZP and I felt like I wasn't breathing normally and I just panicked. I called my Czech friend and she was great she was like OK, I'm gonna send you this sms with a number, just keep breathing and call them immediately. So I did and the person who answered the phone happened to speak English. She had this kind of maternal energy and she was so comforting. I remember clearly, I went there and she was very upfront she said I studied in the UK but I have never done sessions in English, so forgive me. But I was like 'no no just being with you in this room makes me feel so much better' which was true. And they were so generous to me, it was considered crisis intervention and they gave me like three or four sets of it for free. I mean I was just so glad to be going there and I think that in that part of my life I lacked friends and this contact with her helped me a lot... What helped me a lot was that she could see that I really needed help and I could see that she could see it you know and the fact that she was there for me and I knew she would listen to me helped me so much." (American female)

Further examples illustrate that in general, participants found helpful when practitioners expressed positive attitude, authenticity, interest in the client, empathy, willingness to help and to adapt to the client (e.g. speak in the language of the client).

"The therapist helped me a lot, besides being a good listener there were a few things that she could understand and she was able to offer me maybe a different perspective. She had experience with living abroad and she's female and a little bit of feminist. And she didn't have these traditional views on a couple and it helped me a lot that it was close to my views." (American female)

"She had lived a big part abroad herself so she knows how someone feels living a different country, culture, language than your own." (Albanian female)

"I received compassion, insight, a fair look at other ways to examine my problem without being made to feel disbelieved; willingness to work with me if finances became difficult." (British female) 
"Positives were her empathy and listening skills, particularly given that we weren't working in her language." (American female)

"I was lucky to meet a psychologist who tried to understand me despite the incoherent speech and my errors in the Czech language. This psychologist did not pay attention to this. Communication was excellent." (Russian female)

\section{Where can foreigners seek mental health care in Prague?}

Several mental health clinics and practitioners from both private and public practice were contacted during the data collection, in order to find out about the options of mental health services for foreigners and their accessibility. The following part is a general overview of institutions in Prague where foreigners may access help from qualified practitioners, particularly when they find themselves in an urgent situation. It is not meant to be an exhaustive list but rather an overview of the possible options and their description.

Emergency services such as crisis intervention are probably the most ailing area when it comes to mental health care for foreigners. There are two main crisis intervention centers in Prague Bohnice and RIAPS. The former does assist to foreign clients, however, it is primarily focused on the Czech clients so the character of the place does not allow for any complex treatment of foreigners. Also, Bohnice does not have any information in English available online so foreigners are usually not aware that they can seek help there. Information about RIAPS crisis center can be found on the internet in English ${ }^{7}$, however, from participants' and researcher's experience the center does not treat foreigners at all. Based on a personal testimony, RIAPS refers foreigners to hospital $\mathrm{Na}$ Homolce or to General University Hospital (VFN) which do not offer any complex treatment to foreigners either. One of the participants was hospitalized in VFN and described it as "the most pointless thing I've ever done" and further explains "No one tried to get me involved with other patients because hardly anyone from the staff could speak English. It was usually like, 'Oh here comes the English speaker what are we going to do with her?' I just spent a lot of time on my own reading and listening to music. That was not helpful and unbelievably lonely..."

Diakonie, an NGO managed by the Evangelical church, runs a SOS center ${ }^{8}$ that offers free sessions of crisis intervention and they have English speaking therapists on staff. It is a good option for foreigners who seek help urgently and cannot afford to pay higher fees as their services are free of charge. Unfortunately, their website is only in Czech language which makes it difficult for foreigners to find out about their services. Also, the center does not have a psychiatrist on staff and the care consists mostly of short-term ambulant consultations. As a result, there is not any complex crisis intervention for foreign population available in Prague. FOKUS Prague ${ }^{9}$ offers community help to people who suffer from mental health illness. They have an English version of their website and they can be a reliable source of help for foreign clients. Also, there are two non-profit organizations ${ }^{10}$ that offer psycho-social services to foreigners and their activities include psychological consultations and short-term psychotherapy free of charge. They have a website in English and in other languages, and psychotherapists proficient in various foreign languages. However, their focus is mainly on facilitating the integration process of immigrants and psychotherapy is not their primary activity.

\footnotetext{
${ }^{7}$ www.csspraha.cz/en/24941-crisis-center-riaps

${ }^{8}$ www.soscentrum.cz/nase-sluzby/krizova-intervence/

${ }^{9}$ fokus-praha.cz/index.php/en/

${ }^{10}$ InBaze (www.inbaze.cz) \& Association for Migration and Integration (www.migrace.com)
} 
Moreover, advertising free of charge services is complicated as the capacity of the service is limited. Most of the therapists are volunteers and the service is funded only through voluntary contributions and grants.

Furthermore, there is a large population of international students in Prague who study their full degree or who come as exchange students. International students can sometimes access mental health services upon their university. Main public universities such as Charles University or the University of Economics provide free counseling services to the international students, however, in most cases the service is not well promoted. Probably the best system of promotion of the service has the Third Faculty of Medicine at Charles University. There are many international students who study a full time degree at the faculty, and the counseling center has an English speaking psychiatrist/psychotherapist on staff. The center has its own website ${ }^{11}$ both in Czech and English, and students are also informed about the center during their orientation week. Counseling centers of other departments and universities have a less elaborated system of promoting the service. It usually consists only of a brief information on the university website $^{12,13}$. Moreover, the availability of the service is scarce, for instance, the counseling center of Charles University provides help to international students 2 hours/week.

Finally, foreigners may seek help among private practitioners and clinics. A popular website for expatriates offers a list of private practitioners in Prague. ${ }^{14}$ Nonetheless, foreigners need to beware as the list is based on free advertisement and there is no guarantee that the practitioners listed are qualified professionals. Foreigners who seek help through the website should always make sure that the practitioner they choose has an appropriate education and experience. For the wealthier part of the foreign population, Canadian Medical Care ${ }^{15}$ is a private clinic and it is also a suitable place to seek mental health care.

\section{DISCUSSION}

The present study aimed to evaluate foreigners' experience with mental health care in Prague and to identify the barriers that prevent them from receiving an appropriate care.

Several barriers that adversely impact the accessibility and the quality of Prague mental health care were identified. Barriers associated with accessibility of the services are language, cost of mental health services, lack of information about mental health services for foreigners, and long waiting times. These barriers refer to the structural level of cultural competence (Betancourt et al., 2003; Kirmayer, 2012). Barriers associated with quality are low professionalism and cultural differences; they refer to the individual cultural competence of practitioners (APA, 2003, 2013). Although separate categories, the barriers are interconnected and often have a direct influence on one another (e.g. language - information, language - availability, cost professionalism).

In general, the barriers are present in both private and public mental health facilities, yet their prevalence is different. Mental health services in public institutions are usually financially accessible, however, they are tailored to the needs of Czech clients, so the staff is usually not used to working with foreigners and the language barrier is often present. Also, most public mental clinics do not have their website in English, hence, it is difficult to access information about the services without the knowledge of the Czech language.

\footnotetext{
${ }^{11}$ apps.szu.cz/poradna/successfulstudent/?rewrite=poradna/successfulstudent

12 www.cuni.cz/UKEN-189.html

${ }^{13}$ fph.vse.cz/akademicke-centrum/psychologicka-poradna/for-foreign-students/

${ }^{14}$ www.expats.cz/en/prague/directory/therapists/

15 www.canadian.cz/en/specialization/psychology
} 
For instance, Bohnice, the largest mental clinic in Prague, does not have an English version of their website, even though they are able to provide help to foreign clients, and they also run a crisis intervention center which can assist to foreigners in case of emergency.

Information about private practitioners and clinics that work with foreign clients is relatively accessible. They mostly have their own website with information provided in English and sometimes even in other languages. Nonetheless, the quality of their services cannot always be guaranteed as there are no legislative regulations and policies for private 'mental health counselors'. Further, private practitioners and private clinics tend to be expensive and thus inaccessible for foreigners with an average/low income.

Foreigners with permanent residence or with an employment contract in a Czech company have access to public health insurance (e.g. VZP, OZP), which should cover psychiatric care and psychotherapy in institutions that accept their insurance. However, foreigners can rarely benefit from it as foreign-friendly practitioners in public institutions are usually difficult to access. As a result, foreigners with public health insurance often end up seeking help among private practitioners where they mostly cannot use their insurance. This illustrates the fact that only 7 participants in our sample had a direct experience with a public mental health institution.

Barriers linked to the quality of treatment are, from a big part, related to the individual competence of each practitioner. We cannot make any general conclusions about the overall level of professional and cultural competence of Prague practitioners as we do not have enough evidence. In fact, the study did not primarily focus on assessing practitioners' individual competence. Nonetheless, we can infer that deficiencies in the two areas we identified may stem from a lack of training in intercultural issues of mental health practitioners, and from a lack of legislative regulations for mental health care allowing that people without any psychological or medical background offer mental health care services. At present, there are many counselors, coaches, and pseudo-therapists in the private practice who offer all kinds of services of questionable quality for high fees. Moreover, the terms that are commonly used in the field of mental health care such as psychologist, psychotherapist, psychiatrist, psychoanalyst, counselor, coach, etc. are often confusing for general public and it is can be difficult to figure what kind of services one can get.

\section{Practice implications}

Findings of the study suggest that a lot of steps can be taken in order to improve the accessibility and the quality of mental health care for foreigners in Prague.

First, information barrier should be addressed. Our findings suggest that most foreigners access information about mental health care via internet. Hence, mental health institutions that are able to help foreigners must have their website in English. There is a relatively large community of practitioners in Prague such as psychologists, psychotherapists, or psychiatrists, who offer their services to foreign clients. However, they mostly work in their own private practice and they are rarely interconnected between each other and the public mental health institutions. Cooperation between private and public practice in referring foreign clients is not very common and most public institutions do not know where to refer foreigners, if they cannot help them. It would be useful to create an online database with practitioners, who work with foreign clients, both from private and public practice. Such database would help to connect practitioners, help with referrals, and most importantly, it would be extremely beneficial for foreigners, who seek mental health care. In the Czech Republic, a big part of those who seek mental health care turn also to their GP (Höschl, Winkler, \& Pěč, 2012). Hence, an online database could also help GPs in referring clients to appropriate practitioners. 
Second, the language is an important barrier that hinders foreigners' access to mental health care. Our findings suggest that language barrier is most evident in the public institutions. We believe, however, that the overall level of foreign language proficiency among mental health practitioners is high, as the knowledge of English is considered a common skill nowadays. Perhaps as the system of mental health care in Prague is tailored to the Czech population, practitioners are not trained or used to working with foreign clients. The researcher met with several practitioners during the data collection and noticed that many were underestimating their ability to work in a foreign language. Yet, the literature suggests that even with a limited knowledge of client's language practitioners can still try to help. Even if the communication might not be ideal, it can foster the rapport and the client might appreciate just the practitioner's positive attitude and the will to adapt to the client (Martinez, 2013). This underscores one of the participants cited above, who mentioned that a slight language barrier was not important if she felt that the practitioner was trying to help.

On the other hand, we are aware it is impossible that all mental health staff would speak foreign languages. In many Western countries, however, the use of specially trained interpreters is an important part of culturally sensitive practice (Betancourt et al., 2003). In Prague, large public hospitals such as Motol can usually arrange for interpreter service if necessary, yet the use of interpreters in public mental health facilities is practically non-existent. Participants were asked in the questionnaire if they ever experienced interpreter assistance in mental health services (item 17) and none of the participants answered positive to this item. Using interpreter services also in mental health care institutions would be extremely beneficial both for the clients and for the practitioners, and it would significantly improve the cultural competence of the services (Bauer \& Alegría, 2010).

Third, the cost of mental health services prevents many foreigners from accessing appropriate help. Financial barrier is mostly associated with private practitioners and psychotherapeutic services, as there are no regulations for the financial part and practitioners can set the rules of pricing as they wish. As a result, there is a large variability starting from prices around 800 crowns and reaching up to amounts as high as 2500 crowns per session. Such fees can be afforded only by the richest. For most of the population, particularly for the most vulnerable, it is usually out of reach. Also, many private psychotherapists and counselors charge an extra fee for foreign language. We believe that such financial policies are discriminatory and it is ethically wrong to charge higher price based on one's language.

Fourth, crisis intervention is the crucial area of mental health care for foreigners that should be addressed. There are frighteningly few options for foreigners in mental health crisis. Nowadays, the two best options are probably the crisis intervention center in Bohnice and SOS centrum Diakonie. However, neither of those centers provides any complex care to foreigners. For the most part, it consists of brief consultations and, in the case of Bohnice, also of pharmacotherapy. Moreover, none of those centers has their website in English, so many foreigners cannot access information about their services. Perhaps, in the present state of mental health care, it would be impossible to establish a crisis center that would focus solely on the foreign population. Yet, we believe that the first step to address this problem might be a crisis phone line such as Linka důvěry or Bílý kruh bezpečí, reserved for English/Russian speaking population in crisis.

Finally, improving the quality of intercultural mental health care is probably the most challenging part to address. Nonetheless, an important step forward would be a legislative regulation for mental health services which would ensure that only qualified practitioners with an appropriate education and training can provide mental health services. 
Further, incorporating intercultural training into the education of future psychologists would be extremely valuable, as it would increase their awareness of intercultural topics and improve their cultural competence (Aklin \& Turner, 2006). Practitioners interested in intercultural clinical practice may examine the guidelines that American Psychological Association released in $2013^{16}$, they are a useful source of information about culturally competent practice (APA, 2013). Also, the DSM-5 acknowledges the importance of cultural competency and every diagnosis includes information about cultural variations of the symptoms. Even more, the manual dedicates a chapter to the intercultural psychological assessment along with an outline for a semi-structured interview ${ }^{17}$ that systematically evaluates the clients' cultural background during the intake process (American Psychiatric Association, 2013).

In sum, we believe that the situation of mental health care for foreigners in Prague could improve significantly with some basic steps, particularly on the level of the structural cultural competence. The system of mental health care should promote culturally sensitive care and should make the public institutions more accessible to the foreign population. The present situation derives from the diversification of the population of Prague that has occurred during the past two decades. Yet the system of mental health care has not reacted to the shift in the population and as a result, foreign nationals have to overcome many obstacles when accessing an appropriate mental health care.

We endorse The World Health Organization's (2013, p. 3) statement which suggests that "...everyone should be enabled to reach the highest possible level of mental well-being and should be offered support proportional to their needs. Any form of discrimination, prejudice or neglect that hinders the attainment of the full rights of people with mental health problems and equitable access to care should be tackled."

\section{Limitations of the study}

The contribution of this study should be considered also in light of its research limitations. Qualitative research is for the most part based on interpretation. As such, researcher's personality, opinions, previous experience and cultural background necessarily shape the way in which the data are collected, analyzed, and interpreted (Rosso \& Bäärnhielm, 2012). Such risk to the reliability and validity of the findings was addressed through discussion of each step of the research process between the researchers, and through comparing our views on the themes we identified. Also, the fairly large amount of information that were gathered moderated the threat to any potentially biased general conclusions.

Further, collecting data through a non-standardized online questionnaire presents a danger to the validity of the findings. It was important to accurately construct all items so that they reflect the theme of the study and are comprehensible to participants. We tested the pilot version on 3 participants first, to ensure that the items are clear. Also, the topic of the research required that participants could provide information anonymously and indeed, the majority of participants decided not to leave any contact. In the end, 12 participants left their contact email address, 7 out of 27 participants were interviewed, and only 5 interviews were conducted face-to-face. As a result, it was not possible to use thoroughly part to the data from the questionnaires and some of the data might have been misunderstood or misinterpreted by the researchers.

\footnotetext{
${ }^{16}$ American Psychological Association. (2013). Working with immigrant origin clients: an update for mental health professionals. Based on crossroads: the psychology of immigration in the new century. Washington, DC: American Psychological Association.

17 "Cultural Formulation Framework and Interview" (APA, 2013, p. 778).
} 
The inclusion of the Russian sample into the research represents another difficulty, as none of the researches speaks Russian. The construction of the Russian version of the questionnaire was done with a help of a bilingual Czech-Russian translator, and the answers that Russian-speaking participants provided were analyzed with a help of online translator. As such, the language barriers might have prevented the researches from accurately translating and interpreting the information. Nonetheless, the Russian sample represented only a small part of the sample (7) so the amount of potentially biased interpretations did not present a serious threat to the general conclusions about the main findings.

Thirdly, in order to make some general conclusions, it was important to gather a sample that would be representative of the foreign population. The nationality variance of the sample was well achieved, however, the gender inequality is probably one of the main drawbacks of the study, as the sample consisted mostly of female participants ( 24 female participants, 3 male participants). Yet, we believe that our sample may also reflect the gender difference in willingness to seek mental health care, and the willingness to share such personal information to which men may be more reluctant.

\section{CONCLUSION}

The present work provides an important insight into the foreigners' use of mental health services in Prague and the barriers that hinder their access to a good quality care. Further research is needed to support the findings of the study. The main flaw of the present study is the lack of male participants in the sample. It would be useful to gather more information about the use of mental health care from the male foreign population of Prague. Also, the present study focused on the capital city of the Czech Republic, however, there are many foreigners living in other parts of the country. It would be interesting to evaluate the situation in other regions too. Finally, comparing the situation in between countries of the European Union would be extremely valuable. Assessing how countries differ in dealing with mental health care for foreign citizens might help to further integrate and improve the system of mental health care in the EU countries.

\section{REFERENCES}

Aklin, W. M., \& Turner, S. M. (2006). Toward understanding ethnic and cultural factors in the interviewing process. Psychotherapy: Theory, Research, Practice, Training. 43, 50-64. http://dx.doi.org/10.1037/0033-3204.43.1.50

Alcántara, C., \& Gone, J. P. (2014). Multicultural issues in the clinical interview and diagnostic process. In F. L. Leong, L. Comas-Díaz, G. C. Nagayama Hall, V. C. McLoyd, \& J. E. Trimble (Eds.), APA handbook of multicultural psychology, Vol. 2: Applications and training (pp. 153-163). Washington, DC US: American Psychological Association.

Allport, G. W. (1958). The nature of prejudice (Abridged ed.). New York: Doubleday.

American Psychological Association. (2003). Guidelines on multicultural education, training, research, practice, and organizational change for psychologists. American Psychologist, 58, 377-402. 
American Psychological Association. (2013). Working with immigrant-origin clients: An update for mental health professionals. Washington, DC: American Psychological Association. Retrieved from https://www.apa.org/topics/immigration/immigration-reportprofessionals.pdf

American Psychiatric Association. (2013). Diagnostic and Statistical Manual of Mental Disorders DSM-5 (5 $5^{\text {th }}$ ed.). Washington: American Psychiatric Publishing.

Arasaratnam, L. A., \& Doerfel, M. L. (2005). Intercultural communication competence: Identifying key components from multicultural perspectives. International Journal of Intercultural Relations, 29(2), 137-163. https://doi.org/10.1016/j.ijintrel.2004.04.001

Bauer, A. M., \& Alegría, M. (2010). Impact of patient language proficiency and interpreter service use on the quality of psychiatric care: A systematic review. Psychiatric Services, 61(8), 765-773. Retrieved from https://ps.psychiatryonline.org/doi/full/10.1176/ps.2010.61.8.765

Bennegadi, R. (2009). Cultural competence and training in mental health practice in Europe: strategies to implement competence and empower practitioners. Brussels: International Organization of Migration. Retrieved from http://www.minkowska.com/sites/default/files/mental_health_practice_background_paper1.pdf

Betancourt, J. R. (2004). Cultural competence - marginal or mainstream movement? The New England Journal of Medicine, 351(10), 953-955. https://doi.org/10.1056/NEJMp048033

Betancourt, J. R., Green, A. R., Carrillo, J. E., \& Ananeh-Firempong, O. (2003). Defining cultural competence: a practical framework for addressing racial/ethnic disparities in health and health care. Public Health Reports, 118(4), 293-302.

https://doi.org/10.1093/phr/118.4.293

Berry, J. W. (1997). Immigration, acculturation and adaptation. Applied Psychology: An International Review, 46, 5-68. https://doi.org/10.1111/j.1464-0597.1997.tb01087.x

Český statistický úrad. (2016). Cizinci: počet cizinců. Retrieved from https://www.czso.cz/csu/cizinci/cizinci-pocet-cizincu

Draguns, J. G., \& Tanaka-Matsumi, J. (2003). Assessment of psychopathology across and within cultures: Issues and findings. Behaviour Research and Therapy, 41(7), 755-776. https://doi.org/10.1016/S0005-7967(02)00190-0

Höschl, C., Winkler, P., \& Pěč, O. (2012). The state of psychiatry in the Czech Republic. International Review of Psychiatry, 24(4), 278-285. https://doi.org/10.3109/09540261.2012.688730

Hubinková, Z., et al. (Eds.). (2011). Multikulturní poradenství na vysokých školách v České republice: Sbirka př́padových studií. Prague: University of Economics Press, Oeconomica.

Jacob, K. S. (2014). DSM-5 and culture: The need to move towards a shared model of care within a more equal patient-physician partnership. Asian Journal of Psychiatry, 7, 89-91. https://doi.org/10.1016/j.ajp.2013.11.012

Kirmayer, L. (2012). Rethinking cultural competence. Transcultural Psychiatry, 49(2), 149164. Retrieved from https://journals.sagepub.com/doi/pdf/10.1177/1363461512444673 
Kirmayer, L. J., Narasiah, L., Munoz, M., Rashid, M., Ryder, A. G., Guzder, J., Hassan, G., Rousseau, C., \& Pottie, K. (2011). Common mental health problems in immigrants and refugees: General approach in primary care. Canadian Medical Association Journal, 183(12), e959-e967. Retrieved from http://www.cmaj.ca/content/183/12/E959.full

Marsella, A. J., \& Yamada, A. (2013). The study of culture and psychopathology:

Fundamental concepts and historic forces. In F. A. Paniagua, A. Yamada, F. A. Paniagua, A. Yamada (Eds.), Handbook of multicultural mental health: Assessment and treatment of diverse populations, 2nd ed (pp. 3-23). San Diego, CA, US: Elsevier Academic Press.

Martinez, C. (2013). Conducting the cross-cultural clinical interview. In F. A. Paniagua, A. Yamada, F. A. Paniagua, A. Yamada (Eds.), Handbook of multicultural mental health: Assessment and treatment of diverse populations, 2nd ed (pp. 191-204). San Diego, CA, US: Elsevier Academic Press.

Ministerstvo zdravotnictví ČR. (2013). Strategie reformy psychiatrické péče. Retrieved from www.strukturalni-fondy.cz/getmedia/3cba95de-e355-4225-8838-625ee0cf153c/Strategiereformy-psych-pece.pdf?ext=.pdf

Neuliep, J. W. (2014). The Perceptual Context. In Neuliep, J. W. (Ed.), Intercultural communication: A contextual approach (pp. 151-182). Sage Publications.

Raboch, J., \& Wenigová, B. (2012). Mapování stavu psychiatrické péče a jejího směřování v souladu se strategickými dokumenty České republiky (a zahraničí): odborná zpráva z projektu. Praha: Česká psychiatrická společnost. Retrieved from https://www.ceskapsychiatrie.cz/images/stories/OZ_zkr_komplet.pdf

Rosso, M. S., \& Bäärnhielm, S. (2012). Use of the Cultural Formulation in Stockholm: A qualitative study of mental illness experience among migrants. Transcultural Psychiatry, 49(2), 283-301. https://doi.org/10.1177/1363461512442344

U.S. Department of Health and Human Services (USDHHS). (2001). Mental health: Culture, race and ethnicity - A supplement to mental health: A Report of the Surgeon General. Rockville, MD: U.S. Department of Health and Human Services, Public Health Office, Office of the Surgeon General. Retrieved from https://www.ncbi.nlm.nih.gov/pubmed/20669516

Winkler, P., Csémy, L., Janoušková, M., \& Krejníková, L. (2013). Reforma systému psychiatrické péče: mezinárodní politika, zkušenost a doporučení. Praha: Psychiatrické centrum Praha. Retrieved from https://www.nudz.cz/files/common/reforma_systemu_psychiat_pece.pdf

World Health Organization. (2013). The European Mental Health Action Plan. Retrieved from http://www.euro.who.int/_data/assets/pdf_file/0004/194107/63wd11e_MentalHealth3.pdf 


\section{About the authors}

Mgr. Martin Tušl completed his Master's degree in Psychology at Charles University in Prague in 2017, he is currently working as a research assistant at the University of Bologna in Italy.

\section{Contact details:}

Address: University of Bologna, Department of Psychology, via Filippo Re, 10, 40126 Bologna, Italy

E-mail: martin.tusl@unibo.it

PhDr. Markéta Niederlová, Ph.D. completed her Ph.D. in Clinical Psychology at Charles University in Prague in 2002. Her focus is on psychological assessment and she is in charge of several courses for psychology students at Charles University.

\section{Contact details:}

Address: Charles University in Prague, Department of Psychology, Nám. J. Palacha 2, 11638, Prague 1, Czech Republic

E-Mail: marketa.niederlova@ff.cuni.cz

Tušl, M., \& Niederlová, M. (2018). Accessibility and quality of mental health care for foreigners in Prague. E-psychologie, 12(3), 1-23. https://doi.org./10.29364/epsy.322

\section{APPENDIX}

Questionnaire A

\section{Quality and Accessibility of Mental Health Care for Foreigners in Prague}

Dear participant, I'm a psychology student at Charles University currently enrolled in the final year of my Master's program. My interest is focused on intercultural psychology, and I'm writing my Master's thesis about the quality and accessibility of psychological care for foreigners who live in Prague (psychotherapy, psychodiagnostics, crisis intervention, counselling, etc.). In order to gain insight into foreigners' experiences with psychologists/psychotherapists in Prague, I have prepared a short list of questions about your own personal experience. The completion of the questionnaire is anonymous and it will take you about 10 minutes. The data from the questionnaires will be summarized in a final report that will reflect the overall quality and accessibility of psychological care for foreigners in Prague. Also, positive references for psychologists will be used to create an online database of recommended psychologists who work with foreign clients in Prague.

If you have any questions or if you'd like to contact me feel free to do so via e-mail: mental.health.prague@gmail.com Thank you for your participation! 
I identify my gender as

Female

Male

Prefer not to disclose

Age

$18-25$

26-35

$36-45$

$46-55$

$56-65$

66-99

Nationality

Languages spoken (at least conversational level - B1)

Visa status

Short-term visa for a stay up to 90 days (Visa "C")

Long-term visa over 90 days (Visa "D")

Permanent residence

EU

Other (please, specify)

How long have you been living in Prague?

1-3 months

4-7 months

8-12 months

1-3 years

4-7 years

8-10 years

More (please, specify)

\section{Occupation}

Student

Entrepreneur

Employed

Unemployed

Other (please, specify)

Have you ever had a personal experience with a psychologist/psychotherapist in Prague? Yes

No (please, go to question 26)

For the following questions, if you have seen more psychologists in Prague, please consider the most positive experience or the one that had the biggest impact on you. 
What kind of psychologist did you see?

Private

Private hospital/clinic

Public hospital/clinic

Other (please, specify)

Could you briefly describe the reason for your visit? (optional)

How did you search for the psychologist?

Internet

GP referral

Friend referral

Other (please, specify)

How difficult was it to find a psychologist that would meet your needs?

Very easy

Rather easy

Rather difficult

Very difficult

What were the main barriers that you have encountered in accessing mental health services?

From the moment you started searching for a psychologists, how long did it take to get your first appointment?

Less than a week

1-2 weeks

Less than a month

1-2 months

3-4 months

More (please, specify)

How many appointments did you have with the psychologist?

1

$2-5$

6-10

$11-20$

21-30

$31-50$

More (please, specify)

In which language did you communicate? Did the psychologist respect your language preference for communication?

Did the psychologist use an interpreter to facilitate the communication with you?

Yes

No

Partly (please, specify) 
Did you feel comfortable communicating with the psychologist? What made you feel comfortable/uncomfortable?

Did you feel that there were some misunderstandings or uncomfortable situations that might have been due to cultural differences between you and the psychologist?

Did you feel that the psychologist understood well all aspects of your problem? What made you feel this way?

Did the psychologist help you with the problem you came with?

Yes

No

Somewhat (please, specify)

How did you feel about the price you were charged?

Cheap

Adequate

Expensive

Very expensive

Were the expenses covered by your insurance?

Yes

No

Partly (please, specify)

Overall, how would you rate your experience?

Excellent

Good

Neutral

Bad

Terrible

What were the main positives and negatives of your experience?

Would you be able to recommend any competent psychologists/psychotherapists who work with foreign clients in Prague (your positive reference may be used to contact the psychologist)

Anything you would like to add (comments, ideas, recommendations, etc.)? Would you have any suggestions on how to improve the accessibility and quality of mental health services for foreigners in Prague?

Thank you for your time! If you would be willing to further participate in the research (a short interview about your experience), and get information about the results of the study, please leave your e-mail address below or contact me at mental.health.prague@ gmail.com 